\title{
IMPROVED TECHNIQUE FOR CONTROLLING OSCILLATION OF COASTAL MORPHOLOGICAL MODELING SYSTEM
}

\author{
Yun-Chih Chiang \\ Center for General Education, Tzu Chi University, Hualien, Taiwan, R.O.C. \\ Sung-Shan Hsiao \\ Department of Harbor and River Engineering, National Taiwan Ocean University, Keelung, Taiwan, R.O.C., \\ sshsiao@ntou.edu.tw \\ Ming-Chung Lin \\ Department of Engineering Science and Ocean Engineering, National Taiwan University, Taipei, Taiwan, R.O.C.
}

Follow this and additional works at: https://jmstt.ntou.edu.tw/journal

Part of the Engineering Commons

\author{
Recommended Citation \\ Chiang, Yun-Chih; Hsiao, Sung-Shan; and Lin, Ming-Chung (2011) "IMPROVED TECHNIQUE FOR CONTROLLING \\ OSCILLATION OF COASTAL MORPHOLOGICAL MODELING SYSTEM," Journal of Marine Science and Technology: Vol. \\ 19: Iss. 6, Article 6. \\ DOI: $10.51400 / 2709-6998.2204$ \\ Available at: https://jmstt.ntou.edu.tw/journal/vol19/iss6/6 \\ This Research Article is brought to you for free and open access by Journal of Marine Science and Technology. It has been \\ accepted for inclusion in Journal of Marine Science and Technology by an authorized editor of Journal of Marine Science and \\ Technology.
}


IMPROVED TECHNIQUE FOR CONTROLLING OSCILLATION OF COASTAL MORPHOLOGICAL MODELING SYSTEM

Acknowledgements

The work was partially financially supported by the Harbor and Marine Technology Center (HMTC) Project: MOTCIOT-97-H2EB001. 


\title{
IMPROVED TECHNIQUE FOR CONTROLLING OSCILLATION OF COASTAL MORPHOLOGICAL MODELING SYSTEM
}

\author{
Yun-Chih Chiang*, Sung-Shan Hsiao**, and Ming-Chung Lin***
}

Key words: morphological modeling, numerical oscillation, improved technique.

\begin{abstract}
Numerical modeling of coastal morphological evolution is a powerful tool for the planning and design of coastal engineering. The coastal morphological modeling system is based on the sediment conservation law, which couples modules for waves, wave-driven currents, and sediment transport rates. The numerical scheme for the sediment conservation law and nonlinear coupling between these modules can lead to dispersions, diffusions, spurious oscillations and instability problems that are still not well established. Filtering or artificial diffusion are often added to achieve stability. In this paper, several controlling oscillations schemes without filters are described. A stable morphological model is introduced with a combination of methods and is performed well with complex coastal area.
\end{abstract}

\section{INTRODUCTION}

The central concern of nearshore dynamics is the determination of bathymetric changes due to the action of waves and currents in the coastal zone, such as tidal inlets, river mouths, estuaries, bays and coastal ports. It is important to determine the evolution of bed levels for hydrodynamic systems in nearshore regions where waves and flows interact with, and induce significant changes to, coastal topography. Coastal morphological models are indispensable and powerful tools that allow harbor and hydraulic engineers to predict nearshore topography, to analyze the impact of coastal structures, and to verify the planning and design of harbors and coastal defenses. Morphological models are based on various sub-models for

Paper submitted 12/15/09; revised 01/14/11; accepted 04/14/11. Author for correspondence: Sung-Shan Hsiao (e-mail: sshsiao@ntou.edu.tw).

*Center for General Education, Tzu Chi University, Hualien, Taiwan, R.O.C. **Department of Harbor and River Engineering, National Taiwan Ocean University, Keelung, Taiwan, R.O.C.

***Department of Engineering Science and Ocean Engineering, National Taiwan University, Taipei, Taiwan, R.O.C. waves, tidal currents, nearshore currents, and sediment transport, coupled with the sediment transport model. The sediment transport model solves the sediment conservation equation to calculate bed-level evolution. The local sediment transport is first calculated by wave and current sub-models, and the bed form evolution is then computed based on the conservation of sediment and its continual redistribution in time. In the last twenty years, two dimensional depthaveraged coastal morphological models have been developed, and these models have been applied in the short-term (hours to days) and medium-term (months to years).

In morphodynamic models, the governing equations are a nonlinear function of bed level. The sediment transports, which are caused by waves and currents, are also calculated from complicated nonlinear hydrodynamic systems. The nonlinear couplings and numerical scheme errors generate unstable and inaccurate numerical results. Even though the results of all sub-models are accurate and robust, their combination in the sediment conservation equation also leads to numerical oscillations and instabilities [11]. In recently, these problems are addressed with low-pass filters to dissipate spurious high frequency oscillations [2, 11, 15], the bed-slope updating scheme [1, 4, 6-8, 22, 28], high-order time marching schemes [4, 24, 27], predictor-corrector time marching method [8], applying NOC (non-oscillations) scheme to remove spatial oscillations [2, 23] and applying WENO scheme to controlling spatial oscillations $[4,19$, 24].

The aim of this paper is to describe these techniques of above schemes and a robust algorithm for computing bed level change which is flexible enough to handle the nonlinearity present in the sediment conservation equations describing bed evolution in a complex coastal area.

\section{TECHNIQUES OF CONTROLLING OSCILLATIONS}

\section{Governing Equation: Sediment Conservation Law}

The change of bed form in local bottom elevation $z_{b}$ can be computed by solving the conservation equation for sediment mass. In two dimensions, this can be written as: 


$$
\frac{\partial}{\partial t}\left[(1-n) z_{b}+\int_{z_{b}}^{\eta} c d z\right]+\left(\frac{\partial q_{x}}{\partial x}+\frac{\partial q_{y}}{\partial y}\right)=0
$$

where $z_{b}$ is the bed level elevation, defined as positive up from a fixed datum, $x$ and $y$ are horizontal space coordinates, $t$ is time, $n$ is the bed porosity, $\eta$ is the free surface elevation, $c$ is the suspended sediment concentration in the water column per unit area, and $q_{x}$ and $q_{y}$ are the total volumetric sediment transport rates (unit: $\mathrm{m}^{3} / \mathrm{sec}$ ) in the $x$ - and $y$ - directions, respectively.

In general, the suspended load contribution of sediment can be consisted in sediment flux, and the sediment transport conservation equation can be reduced to:

$$
\frac{\partial z_{b}}{\partial t}+\frac{1}{1-n}\left(\frac{\partial q_{x}}{\partial x}+\frac{\partial q_{y}}{\partial y}\right)=0
$$

\section{Feedback by Bed-slope Updating Scheme}

As mentioned before, the morphodynamic system to be calculated when coupling the hydrodynamic (waves and wavedriven currents) and sediment transport into the morphological models (governed by conservation equation of sediment) is inherently unstable. This highly non-linear system will lead to diffusion if the effect of bed-slope variations in time is not taken into account $[6,7,28]$. In the morphological model, the linear stability analysis of bed-level and quasi-steady conditions for waves and currents are assumed. The waves and currents are assumed to remain unchanged during the entire calculation period, while the bathymetry does vary. Under this assumption, the sediment transport rates obtained from waves and currents remains unchanged over the same time duration. Even though the wave orbital velocity and current velocity remain unchanged, the bed level changes at every time step. This inconsistency implies that some quantities related to bed level, such as the friction factor and the sediment transport direction factor will also change.

In order to modify sediment transport with bed form slope, the down slope gravitational transport rate is the most commonly utilized while the bed-level changes are greater than a threshold value $[1,3,6,7,20,28]$. Consequently, the conservation equation of sediment mass coupled with the bedslope updated terms in two-dimensions can be rewritten as:

$$
\begin{aligned}
\frac{\partial z_{b}}{\partial t}+ & \frac{\partial}{\partial x}\left(q_{x 0}-\varepsilon_{x x}\left|q_{x 0}\right| \frac{\partial z_{b}}{\partial x}-\varepsilon_{x y}\left|q_{x 0}\right| \frac{\partial z_{b}}{\partial y}\right) \\
& +\frac{\partial}{\partial y}\left(q_{y 0}-\varepsilon_{y y}\left|q_{y 0}\right| \frac{\partial z_{b}}{\partial y}-\varepsilon_{y x}\left|q_{y 0}\right| \frac{\partial z_{b}}{\partial x}\right)=0
\end{aligned}
$$

The brackets of Eq. (3) contains the diffusion modified terms. These terms show that the effect of bed slope and the value of transport rates play an important role as diffusion parameters. The stability of the morphological scheme is based on these diffusion terms under control. Consequently, these diffusivity constants $\varepsilon_{x x}, \varepsilon_{x y}, \varepsilon_{y x}$ and $\varepsilon_{y y}$ should be chosen carefully and sediment transport rates in Eq. (3) should be updated in every time step after the new bed elevation is computed.

We recommend that the modified bed-slope feedback should be processed at every time step. It is very effective for the removal oscillations for long term simulations.

\section{Controlling Oscillations in Spatial Discretization}

In order to control the oscillations in space for the morphological model, there are several numerical schemes as reviewed by Callaghan et al. [2] and Long et al. [19]. Among these oscillation removal schemes, the NOC and WENO scheme are more stable finite-difference schemes than the others.

\section{1) WENO Scheme}

The WENO schemes are based on the essentially nonoscillatory (ENO) schemes, which were first developed by Harten et al. [10] in the form of finite volume schemes and were later improved by Shu and Osher [25]. The ENO schemes are generalizations of the total variation diminishing (TVD) schemes of Harten [9]. The TVD schemes are designed so that the total variation of specific quantity in space remains constant or only decrease in time. During the solution process, there will be no new extrema generated. In other words, the TVD schemes typically degenerate to first-order accuracy at locations with smooth extrema, while the ENO schemes maintain high-order accuracy. The key idea of the ENO schemes is to use the smoothest stencil among several candidates to approximate the fluxes at the cell boundaries to high order and at the same time to avoid spurious oscillations near shocks and discontinuities. The WENO schemes process one step further by taking a weighted average of all candidates, and the weights are adjusted by the local smoothness.

The first version of WENO schemes was developed by Liu et al. [18] for one-dimensional conservation laws of fluid mechanics. Jiang and Shu [13] applied the scheme to multidimensional cases with a new weighting procedure to obtain optimized accuracy. Later, Jiang and $\mathrm{Wu}$ [14] extended a high-order $\left(5^{\text {th }}\right)$ accurate WENO finite difference scheme, which has successfully attained comparable accuracy with fewer time-steps in computations. Shao et al. [24] first applies the WENO scheme to solve the one-dimensional conservation equation of sediment mass and study the evolution of periodic sand bars in the presence of waves at the resonant Bragg frequency. Long et al. [19] use the Euler-WENO schemes, based on first order explicit time discretization with the WENO scheme, to study the evolution of periodic alternating sand bars in a rectangular open channel with gravity flow. Chiang et al. [4] applied the bed-slope feedback, 3 levels 2 time-steps, WENO morphological scheme to calculate topography changes of complex coastal area under waves and currents, and found that the stability was performed very well. 
The full detail of the WENO scheme applied with coastal morphological modeling can be found in [4].

The key of inaccuracy of numerical morphological modeling is to obtain the characteristic phase velocity of bedform variation to modified sediment fluxes. Fortunately, another advantage of WENO scheme is that split sediment fluxes only involve the sign of characteristic bedform velocity instead of accurate calculations.

\section{2) NOC Scheme}

NOC scheme is a general non-oscillating scheme originally developed by Nessyahu and Tadmor [21] and extended to 2D by Jiang et al. [12]. It solves multidimensional hyperbolic fluid conservation equations using a staggered grid method, again directly utilizing fluxes. It is similar to be applied with sediment conservation equation, and directly using sediment fluxes is good for avoiding the estimation of characteristic bedform velocity. The examples of NOCS applications for coastal area include linear oblique advection, the two-dimensional Burger and Euler equations and the onedimensional shallow water wave equations [29]. Their approach uses two staggered grids, which are moving the calculated results from one grid to another half grid with every time step. However, the staggered grid system, while minimizing scheme diffusion is impractical for morphological models consisting of a looped arrangement of individual components for sediment transport caused by waves and currents. According to Saint-Cast [23], there is an extension of the original scheme where the new solution was initially determined on the staggered grid and then reconstructed on the original grid [12]. This extension is easily integrated into looped morphological models for the NOC scheme.

The NOC scheme was first applied for coastal morphological modeling by Saint-Cast [23] with the purpose of explaining ridge and runnel formation on sand beaches exposed to consistent north Atlantic swells. The work by Saint-Cast [23] included initial testing against analytical solutions and simulations of an idealized crescent shape barred beach evolutions. Callaghan et al. [2] utilize the NOC scheme with an idealized river entrance, perpendicular to a straight beach with constant slope, under waves and currents and show its stability by comparison with other schemes.

\section{Controlling Oscillations in Temporal Discretization}

As mentioned before, the inaccuracy of bed-level simulation in every time-step is caused by discretization errors and oscillation factors from the sub-models of waves, currents, or sediment transport rates. They will lead to diffusions and dispersions in the long term. There are three typical techniques for controlling oscillations in temporal discretization as following.

\section{1) Explicit Two-Step, Three-Time-Level Finite Difference Scheme}

In this subsection, the explicit two-step, three-time-level finite difference scheme with stagger grid is introduced [4]
This technique can be easily implemented in time discretization and does not lead to a significant CPU time increases. The gradient of sediment fluxes is expanded at half grid position and the bed-level is calculated at original grid position. It is convenient to apply the operator of WENO scheme with approximated sediment fluxes. For one-dimensional sediment conservation problem, Eq. (3) becomes:

Step 1:

$$
\frac{z_{b i}^{n+1 / 2}-z_{b i}^{n}}{\Delta t / 2}+\frac{1}{1-n} \frac{\hat{q}\left(q_{0}, z_{b i}^{n}\right)_{i+1 / 2}-\hat{q}\left(q_{0}, z_{b i}^{n}\right)_{i-1 / 2}}{\Delta x}=0
$$

Step 2:

$\frac{z_{b i}^{n+1}-z_{b i}^{n}}{\Delta t}+\frac{1}{1-n} \frac{\hat{q}\left(q_{0}, z_{b i}^{n+1 / 2}\right)_{i+1 / 2}-\hat{q}\left(q_{0}, z_{b i}^{n+1 / 2}\right)_{i-1 / 2}}{\Delta x}=0$

where the $\hat{q}()$ is the operator of WENO scheme. This scheme gives 2 nd order accuracy $\mathrm{O}\left(\Delta t^{2}\right)$ in time.

\section{2) TVD-Runge-Kutta Scheme}

TVD (Total Variation Diminishing) schemes are designed such that the total variance of the solution $\mathrm{TV}=\int_{-\infty}^{+\infty}\left|\partial_{\mathrm{zb}} / \partial x\right| d x$ will remain constant or only decrease in time. During the solution process, there will be no new extrema generated. TVD scheme were often proposed based on existing schemes. Shao et al. [24] and Shu and Osher [25] applied a TVDRunge-Kutta (TVD-RK) scheme for 3rd order time integration of Eq. (2). The TVD-RK scheme can be summarized as an algorithm of 5 steps:

The 1st step consists of an Euler forward step to get time level $n+1$ :

$$
\frac{1}{\Delta t}\left(z_{b}^{n+1}-z_{b}^{n}\right)+\frac{\partial}{\partial x}\left(\frac{1}{1-n} q\left(z_{b}^{n}\right)\right)=0
$$

The 2nd step uses a second forward step to time level $n+2$ :

$$
\frac{1}{\Delta t}\left(z_{b}^{n+2}-z_{b}^{n+1}\right)+\frac{\partial}{\partial x}\left(\frac{1}{1-n} q\left(z_{b}^{n+1}\right)\right)=0
$$

The 3rd step uses an averaging step to obtain an approximation solution at $n+1 / 2$ :

$$
z_{b}^{n+1 / 2}=\frac{3}{4} z_{b}^{n}+\frac{1}{4} z_{b}^{n+2}
$$

The 4th step uses a 3rd Euler step to get time level $n+3 / 2$ :

$$
\frac{1}{\Delta t}\left(z_{b}^{n+3 / 2}-z_{b}^{n+1 / 2}\right)+\frac{\partial}{\partial x}\left(\frac{1}{1-n} q\left(z_{b}^{n+1 / 2}\right)\right)=0
$$


the 5th step uses another averaging step finally to get solution at time level $n+1$ :

$$
z_{b}^{n+1}=\frac{1}{3} z_{b}^{n}+\frac{2}{3} z_{b}^{n+2 / 3}
$$

\section{3) Predictor-Corrector Method}

As mention before, instability problems appear to originate from the explicit discretization of the sediment conservation equation, Fortunato and Oliveira [8] recommend a predictorcorrect scheme was implemented and performed well. It is shown as below:

Predictor step: an estimate of depth at time $n+1$ is first calculated as:

$$
h^{(p)}=h^{n}+\frac{1}{1-n} \nabla \int_{n}^{n+2} q\left(u(t), \eta(t), h^{n}\right) d t
$$

Corrector step: a fully or semi-implicit scheme is applied with the correction step as:

$$
h^{n+1}=h^{n}+\frac{1}{1-n} \nabla \int_{n}^{n+2} q\left(u(t), \eta(t), h^{*}\right) d t
$$

where $h$ is depth, $h^{*}=\alpha h^{(p)}+(1-\alpha) h^{n}, \alpha$ is the implicitness parameter in $[0,1]$. Eqs. (11) and (12) can be repeated iteratively for a user-specified number of correction cycles. This scheme gives 2 nd order accuracy $\mathrm{O}\left(\Delta t^{2}\right)$ in time.

\section{THE MORPHOLOGICAL MODELING SYSTEM}

Consider the computing efficiency, stability and accuracy of numerical schemes, we recommend a bed-slope updating, 2 steps with 3-time-levels (2nd order accuracy), WENO morphodynamic scheme (5th order accuracy) to be applied with complex coastal estuary area. The hydraulic modeling system for waves and currents is suggested by Lin et al. [17], and the sediment transport modeling is suggested by Chiang et al. [5]. It is briefly describe as following. The procedure of the morphological modeling system is shown as Fig. 1.

\section{Hydraulic Modeling}

In this study, the hydraulic modeling include waves and wave-driven currents, are calculated by Eqs. (13)-(19). The governing equations for the wave field used here are [17]:

$$
\begin{aligned}
& \frac{1}{a C_{w} C_{g}}\{(\vec{U} \cdot \vec{\nabla} a)[(\vec{U} \cdot \vec{\nabla})+(\vec{\nabla} \cdot \vec{U})]\} \\
& -\frac{1}{a}\left[\nabla^{2} a+\frac{1}{C_{w} C_{g}}\left(\vec{\nabla} C_{w} C_{g} \cdot \vec{\nabla} a\right)\right]-k^{2}+|\vec{\nabla} S|^{2}=0
\end{aligned}
$$

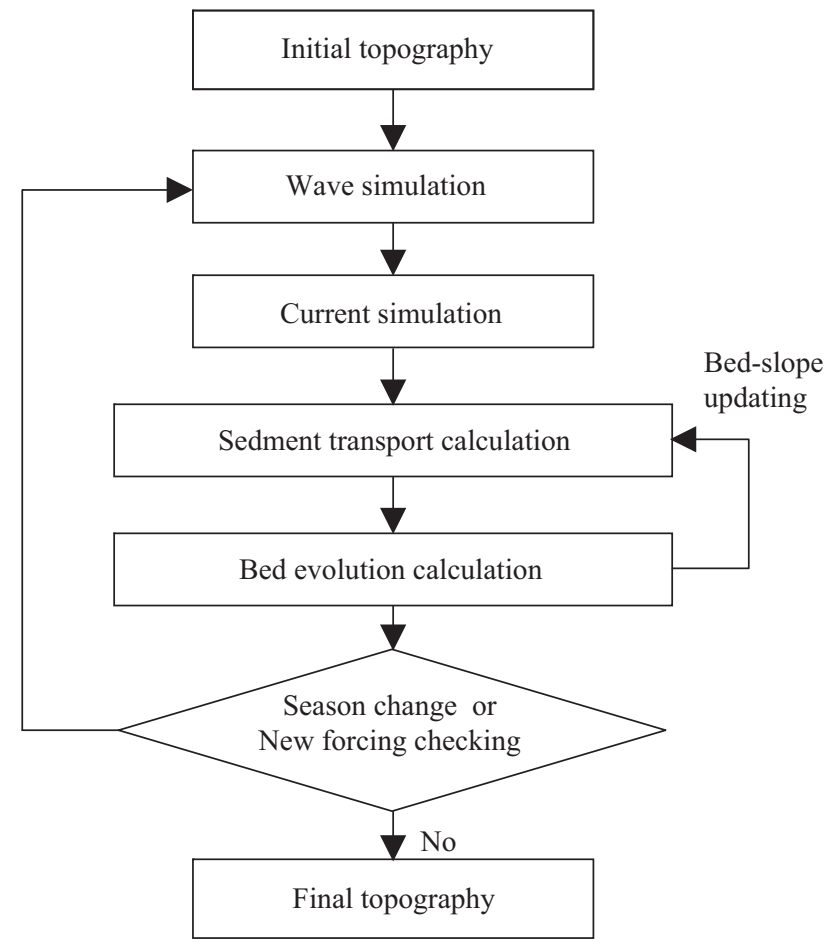

Fig. 1. The procedure of the coastal morphological modeling system.

$$
\begin{gathered}
\vec{\nabla} \cdot\left[a^{2} \sigma\left(\vec{U}+\vec{C}_{g}\right)\right]=0 \\
\frac{\partial}{\partial x}(|\vec{\nabla} S| \sin \theta)-\frac{\partial}{\partial y}(|\vec{\nabla} S| \cos \theta)=0
\end{gathered}
$$

where a is the wave amplitude, $C_{w}$ is the wave celerity, $C_{g}$ is the group wave velocity, $U$ is the mean current, $\nabla$ is the gradient operator, $k$ is the wave number, $S$ is the wave phase function, and $\theta$ is the wave angle. In the surf zone, Eq. (14) is modified with energy dissipation as:

$$
\begin{aligned}
& \vec{\nabla} \cdot\left[a^{2} \sigma\left(\vec{U}+\vec{C}_{g}\right)\right]=\vec{\nabla} \cdot\left[\frac{2 g}{\rho} \frac{E}{\sigma}\left(\vec{U}+\vec{C}_{g}\right)\right] \\
& =-\frac{5}{8} \frac{g^{2} k_{B}}{\sigma^{2}} \frac{\tan \beta}{1+\frac{3 \gamma^{\prime 2}}{2}} \frac{1}{\sqrt{1-\frac{c^{\prime}}{\gamma^{\prime}}}} \sqrt{\frac{H_{B} / 2-c^{\prime} h_{B}}{\gamma^{\prime} h_{B}}}\left(H_{B}\right)^{2}
\end{aligned}
$$

where the subscript $B$ indicates grid position in surf zone, $E$ is the wave energy, $H$ is the wave height, $\sigma$ is angular frequency, $\rho$ is the water density, $h$ is the depth from mean water level, $c$, is $a / h$ in the recovery zone, and $\tan \beta$ is the slope of the beach.

The governing equations for the wave driven currents flow field are [17]:

$$
\frac{\partial \eta}{\partial t}+\frac{\partial}{\partial x}[U(h+\eta)]+\frac{\partial}{\partial y}[V(h+\eta)]=0
$$




$$
\begin{gathered}
\frac{\partial U}{\partial t}+U \frac{\partial U}{\partial x}+V \frac{\partial U}{\partial y}=f U-g \frac{\partial \eta}{\partial x}+\frac{1}{\rho}\left(\frac{\partial \tau_{x x}}{\partial x}+\frac{\partial \tau_{y x}}{\partial y}\right) \\
+\frac{1}{\rho(h+\eta)}\left(\tau_{s x}-\tau_{b x}\right)-\frac{1}{\rho(h+\eta)}\left(\frac{\partial S_{x x}}{\partial x}+\frac{\partial S_{y x}}{\partial y}\right) \\
\frac{\partial V}{\partial t}+U \frac{\partial V}{\partial x}+V \frac{\partial V}{\partial y}=-f V-g \frac{\partial \eta}{\partial y}+\frac{1}{\rho}\left(\frac{\partial \tau_{x y}}{\partial x}+\frac{\partial \tau_{y y}}{\partial y}\right) \\
+\frac{1}{\rho(h+\eta)}\left(\tau_{s y}-\tau_{b y}\right)-\frac{1}{\rho(h+\eta)}\left(\frac{\partial S_{x y}}{\partial x}+\frac{\partial S_{y y}}{\partial y}\right)
\end{gathered}
$$

where $U$ and $V$ are depth-integrated-averaged flow velocities, $\eta$ is the elevation, $f$ is the Coriolis force coefficient, $\tau_{x x}, \tau_{x y}, \tau_{y x}$, $\tau_{y y}$ are the Reynolds stresses, $\tau_{s x}, \tau_{x y}$ are the wind shear stresses on the surface, $\tau_{b x}, \tau_{b y}$ are the bottom friction stresses, and $S_{x x}$, $S_{x y}, S_{y x}, S_{y y}$ are the radiation stresses (time- averaged residual wave momentum fluxes).

\section{Sediment Transport Modeling}

The experimental validations of alongshore and offshore transport rate suggested by Chiang et al. [5], which is applicable for west Taiwan coastal areas are employed:

$$
\begin{gathered}
q_{x}=q_{c}\left(u+U_{r}\right) \\
q_{y}=q_{c}\left(v+V_{r}\right) \\
q_{c}=\left\{A_{1} f_{c}\left[\left(u+U_{r}\right)^{2}+\left(v+V_{r}\right)^{2}\right]+A_{2}\left(U_{w}{ }^{2}-U_{w c}{ }^{2}\right)\right\} / g \\
U_{w}=\sqrt{\frac{\tau_{m}}{\rho}}=\sqrt{\frac{f_{w}}{2}} \times U_{w \max }, U_{w \max }=\frac{\pi H}{T \sinh (k h)} \\
U_{w c}=8.41 \times d_{50}{ }^{11 / 32} \\
f_{c}=g / C_{c}{ }^{2} \\
0.00251 \times \exp \left(5.21 \times \exp \left(\frac{A}{k_{s}}\right)^{-0.19}\right), \frac{A}{k_{s}}>1.57 \\
0.3, \frac{A}{k_{s}} \leq 1.57 \\
A=\frac{H}{2} \sinh (k h)
\end{gathered}
$$

where $u$ and $v$ are the depth integrated average current velocity in the $x$ - and $y$-directions, respectively; $U_{r}$ and $V_{r}$ are the average equivalent river flow velocity in the $x$ - and $y$ - directions; $A_{1}$ and $A_{2}$ are the coefficients of sediment transport due to currents and waves; $f_{c}$ and $f_{w}$ are the friction factors for mean current and wave orbital fluid motion; $U_{w}$ and $U_{\text {wmax }}$ are the shear velocity and its maximum velocity due to wave motion; $U_{w c}$ is the critical shear velocity for the inception of particle motion; $g$ is the gravitational acceleration; $C_{c}$ is the nondimensional Chezy coefficient; $d_{50}$ is the median grain diameter; $A$ is the semi-orbital excursion; $H$ is the wave height; $T$ is the wave period; $k$ is the wave number; and $h$ is the water depth.

\section{Morphological Schemes}

The bed-slope feedback updating, 2 steps with 3-timelevels, WENO morphological scheme with accuracy $\mathrm{O}\left(\Delta t^{2}\right.$, $\left.\Delta x^{5}, \Delta y^{5}\right)$ is shown as below:

Step 1:

$$
\begin{aligned}
& \frac{z_{b i, j}^{n+1 / 2}-z_{b i, j}^{n}}{\Delta t / 2}+\frac{1}{1-n} \frac{\hat{q}_{x}\left(q_{x 0}, z_{b i}^{n}\right)_{i+1 / 2, j}^{n}-\hat{q}_{x}\left(q_{x 0}, z_{b i}^{n}\right)_{i-1 / 2, j}^{n}}{\Delta x} \\
& +\frac{1}{1-n} \frac{\hat{q}_{y}\left(q_{y 0}, z_{b i}^{n}\right)_{i, j+1 / 2}^{n}-\hat{q}_{y}\left(q_{y 0}, z_{b i}^{n}\right)_{i, j-1 / 2}^{n}}{\Delta y}=0
\end{aligned}
$$

Step 2:

$$
\begin{aligned}
& \frac{z_{b i, j}^{n+1}-z_{b i, j}^{n}}{\Delta t}+\frac{1}{1-n} \frac{\hat{q}_{x}\left(q_{x 0}, z_{b i}^{n+1 / 2}\right)_{i+1 / 2, j}^{n+1 / 2}-\hat{q}_{x}\left(q_{x 0}, z_{b i}^{n+1 / 2}\right)_{i-1 / 2, j}^{n+1 / 2}}{\Delta x} \\
& +\frac{1}{1-n} \frac{\hat{q}_{y}\left(q_{y 0}, z_{b i}^{n+1 / 2}\right)_{i, j+1 / 2}^{n+1 / 2}-\hat{q}_{y}\left(q_{y 0}, z_{b i}^{n+1 / 2}\right)_{i, j-1 / 2}^{n+1 / 2}}{\Delta y}=0
\end{aligned}
$$

\section{Stability Condition Analysis}

The stability requirement of most morphological schemes is the Courant number $\left|\mathrm{C}_{i} \Delta t / \Delta x\right| \leq 1$, and the large Courant numbers observed in the simulation of morphological evolutions suggest that reducing the time steps could improve the stability of the numerical schemes. However, this will increase the computational demand. Fortunately, if the diffusion terms of Eq. (3) could be properly eliminated, the limit of Courant number could be great than unity. This can be done by carefully giving the values of the diffusivity constants $\left(\varepsilon_{x x}\right.$, $\varepsilon_{x y}, \varepsilon_{y x}$ and $\left.\varepsilon_{y y}\right)$. Some diffusivity constants have been suggested for real coastal environments. Watanabe [28] suggested that the values are determined empirically through experiments. Struiksma et al. [26] and Cayocca [3] used $\varepsilon_{x x}=$ $\varepsilon_{y y}=4$, and Kuroiwa and Kamphuis [16] suggest $\varepsilon_{x x}=\varepsilon_{y y}=2$. Chiang et al. [4] recommend $\varepsilon_{x x}=\varepsilon_{y y}=4$ and $\varepsilon_{x y}=\varepsilon_{y x}=2$ for complex coastal area. The diffusivity constants were set to $\varepsilon_{x x}=\varepsilon_{y y}=4$ and $\varepsilon_{x y}=\varepsilon_{y x}=2$ in following simulation test. 


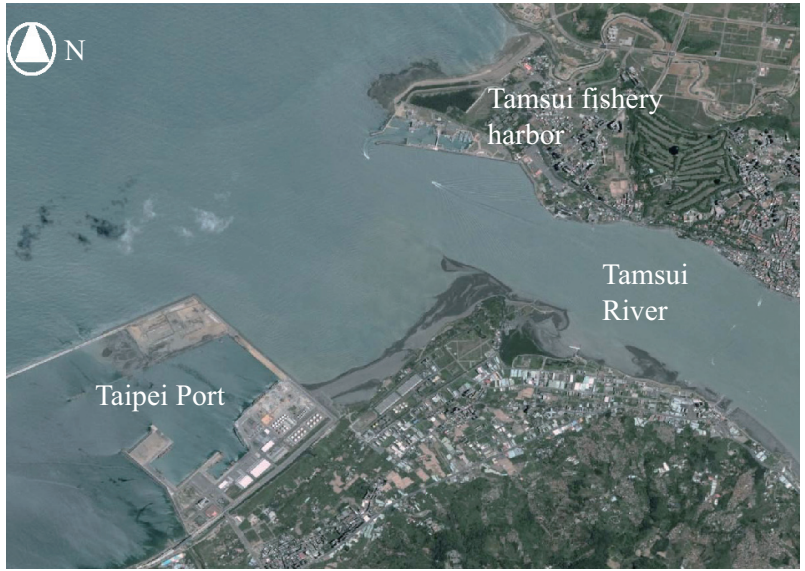

Fig. 2. The simulation site between Taipei Port and Tamsui River.

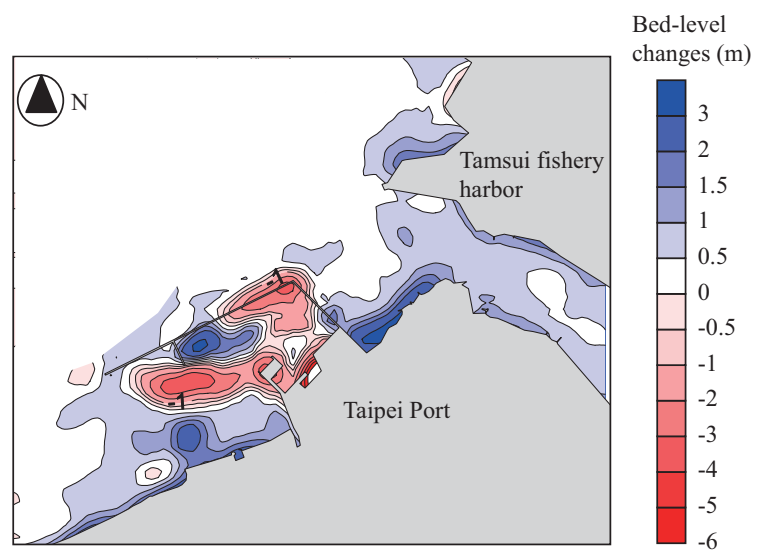

Fig. 3. The topography changes between 2005 April and 2006 April survey data.

\section{RESULT AND DISCUSSION}

\section{Test: Topography Changes between the Taipei Port and Tamsui Estuary}

\section{1) Site description}

The controlling oscillation morphological model is tested by the complex topography in the Taipei county coastal area of western Taiwan. The simulation area (Fig. 2) is between Tamsui River and northern breakwater of Taipei Port, which is $7.0 \mathrm{~km}$ long in the alongshore direction and $3.5 \mathrm{~km}$ wide in the on-off shore direction with a maximum depth of around 35.0 $\mathrm{m}$. The median diameter of the beach sand is $D_{50}=0.25 \mathrm{~mm}$. This area has not only complex depth contours but also large coastal structures. The morphodynamic evolution of the site is driven by waves, waves driven current, tidal current and Typhoon waves and flood. The dominant wave is the winter east-northerly monsoon waves between September and March and the summer west-southerly monsoon waves between April and August. The winter characteristic significant wave height $H_{1 / 3}$ is $2.0 \mathrm{~m}$ and the significant wave period $T_{1 / 3} 7.5 \mathrm{sec}$, and
Table 1. The table of numerical conditions in one year of simulation time.

\begin{tabular}{|l|l|l|}
\hline Stage & Duration & Simulation wave condition \\
\hline 1. Summer monsoon & 150 days & WSW direction, $\mathrm{H}=1.2 \mathrm{~m}, \mathrm{~T}=6.0 \mathrm{~s}$ \\
\hline 2. Typhoon & 5 days & WNW direction, $\mathrm{H}=4.5 \mathrm{~m}, \mathrm{~T}=8.9 \mathrm{~s}$ \\
\hline 3. Winter monsoon & 210 days & NNE direction, $\mathrm{H}=2.0 \mathrm{~m}, \mathrm{~T}=7.5 \mathrm{~s}$ \\
\hline
\end{tabular}

the summer characteristic significant wave height $H_{1 / 3}$ is $1.2 \mathrm{~m}$ and the significant wave period $T_{1 / 3} 6.0 \mathrm{sec}$.

The changes between 2005 April and 2006 April survey data are shown as Fig. 3. There are two characteristic changes in this site, one is siltation in coastal area between breakwater and estuary, and the other is also siltation in southern riverside inside the Tamsui River.

\section{2) Simulations set-up}

There are three durations of morphological simulation in one year. They are the duration of summer monsoon, the duration of typhoon, and the duration of winter monsoon. During monsoon period, the flow field is added by waves driven currents and tidal period averaged currents. In the duration of typhoon, the typhoon waves condition, storm surge waterlevel, and characteristic flood discharge are employed. Numerical conditions are shown as Table 1 .

The selected sediment coefficients are: $A_{1}=1.5$ and $A_{2}=$ 2.5. The spatial grid sizes of $\Delta x=\Delta y=20 \mathrm{~m}$ are used in all models (including the sub-models for waves and currents). The time step interval of $\Delta t=1 \mathrm{~s}$ is used for the nearshore current sub-model and $\Delta t=60 \mathrm{sec}$ for the morphological model.

\section{3) Results and Analysis}

In order to demonstrate the accuracy and stability of modeling performance, the results with and without controlling oscillation schemes have been compared. The wave fields of summer monsoon, winter monsoon and typhoon are shown in Figs. 4-6. The flow field of high/low water level during summer monsoon and winter monsoon are shown in Figs. 7-10. The flow fields of wave-driven currents during different monsoon are shown in Figs. 11 and 12. The morphodynamic results simulated after one year without and with controlling oscillation schemes are shown in Figs. 13 and 14. We can easily find the accuracy and stability by comparison with Figs. 13 and 14 . The common instability of the morpholodynamic long-term simulations is that strong spurious oscillations can be generated near shocks or steep fronts in the surf zone. It is unreasonable for the bed-slope exceeding the rest angle of sand under water $[2,4,19]$. Fig. 13 shows the general features of the morphological response without controlling oscillation schemes after one year. Some Salient and serration of contours have formed in the lee of the Taipei Port breakwater. These oscillations are smoothed out by these schemes as shown in Fig. 14, there is no any shock or steep changes in the 


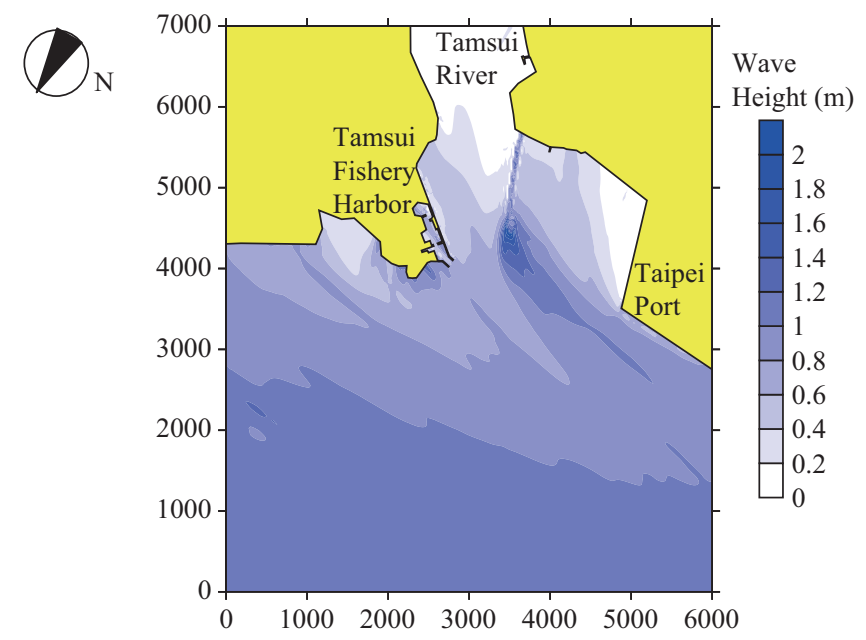

Fig. 4. Wave field during summer monsoon.

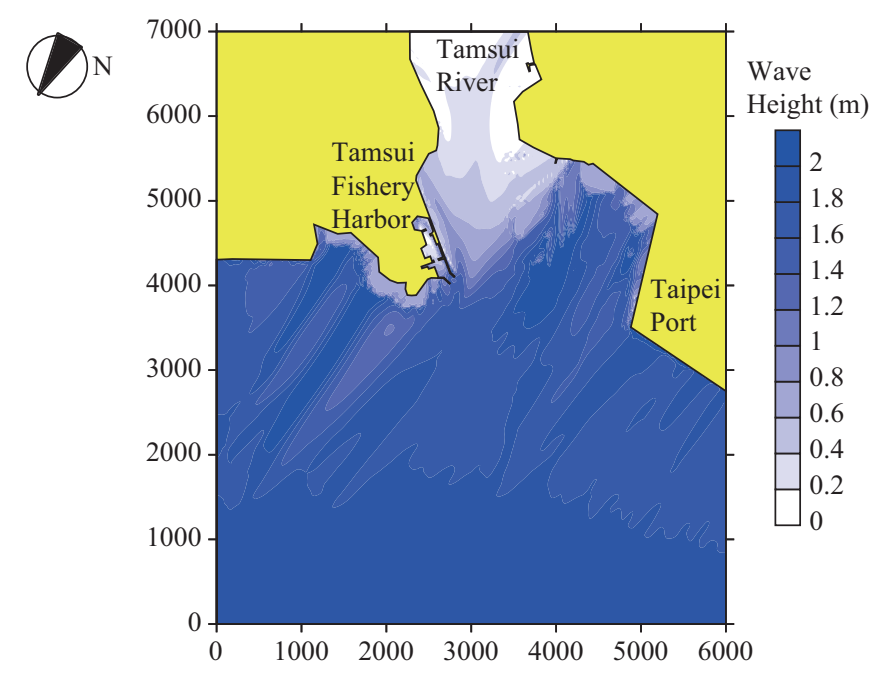

Fig. 5. Wave field during winter monsoon.

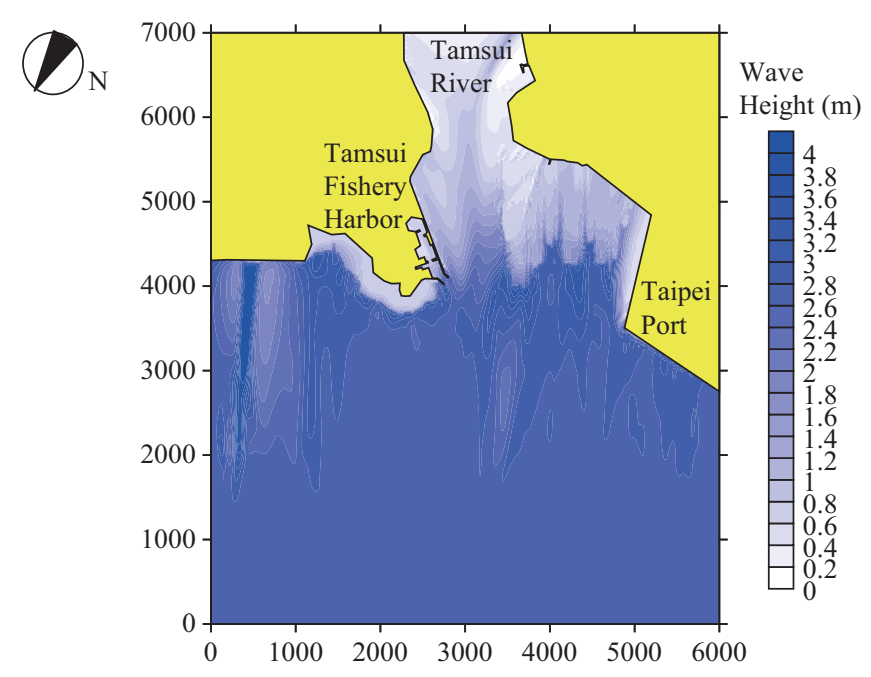

Fig. 6. Wave field during typhoon.

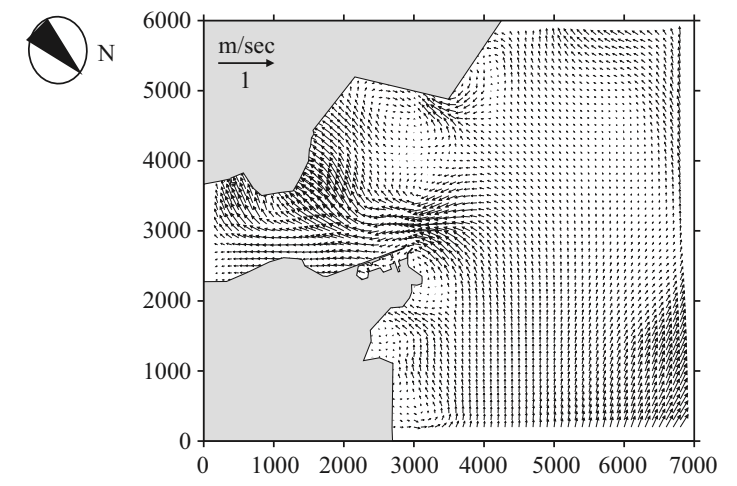

Fig. 7. Flow field of high tidal currents during summer monsoon.

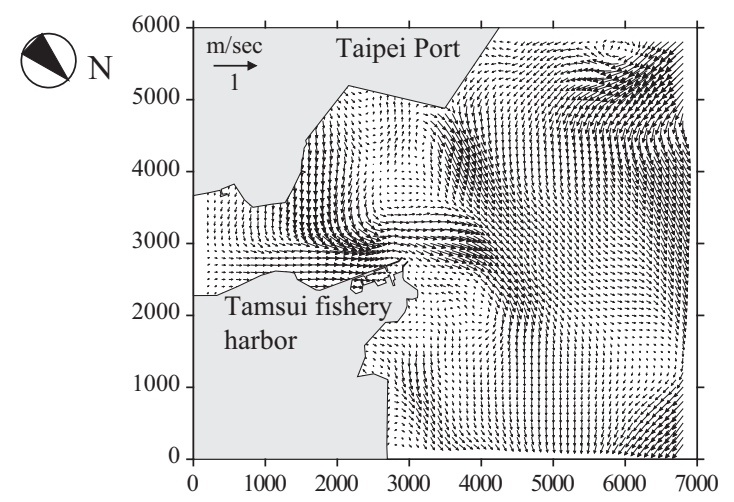

Fig. 8. Flow field of ebb tidal currents during summer monsoon.

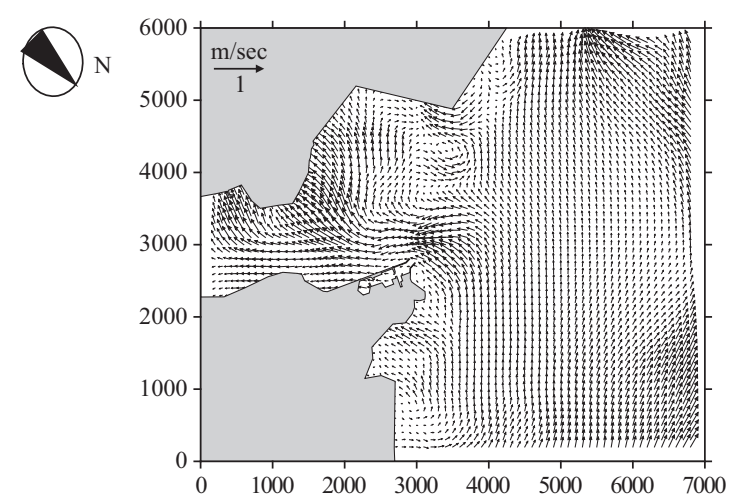

Fig. 9. Flow field of high tidal currents during winter monsoon.

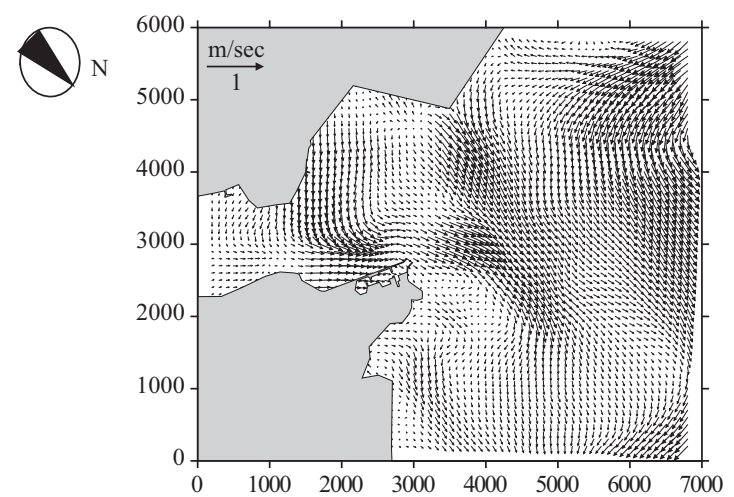

Fig. 10. Flow field of ebb tidal currents during winter monsoon. 


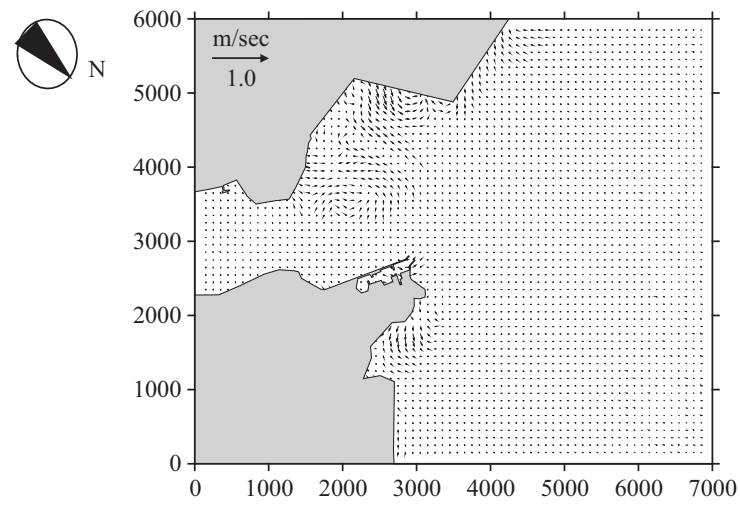

Fig. 11. Flow field of nearshore current during summer monsoon.

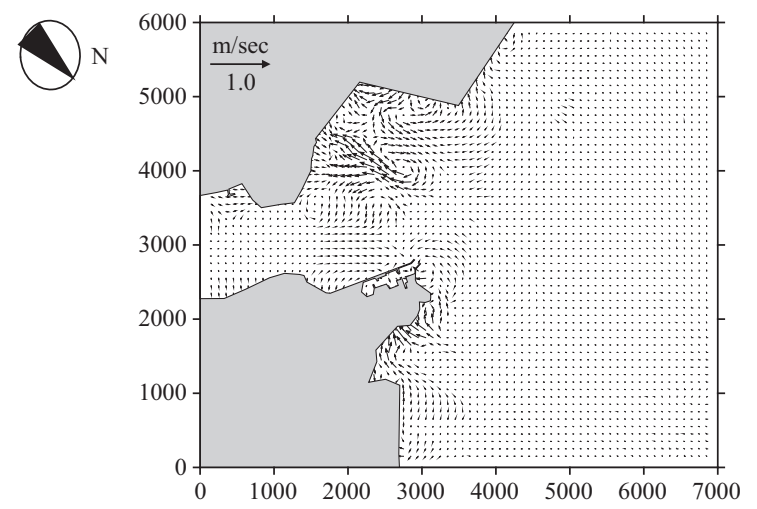

Fig. 12. Flow field of nearshore current during winter monsoon.

results of morphodynamic evolution after one year. This shows that the two-step, three-time-level method can improve the accuracy and stability for the real complex coastal area.

\section{CONCLUSIONS}

Several techniques to control oscillations in morphodynamic models over the past decades were summarized. The bed-slope updated, 2-step 3-time-level, and WENO scheme were presented and illustrated with the complex coastal estuary area. It performed well subject to waves, wave-driven currents, period averaged tidal currents, and storm waves and currents. Comparison with survey data and simulation without controlling oscillation schemes, it is sufficiently demonstrated that our recommended modeling provides a significant improvement for accuracy and stability in real complex coastal area. With the diffusivity constants $\varepsilon_{x x}=\varepsilon_{y y}=4$ and $\varepsilon_{x y}=\varepsilon_{y x}=2$, the Courant number can generally increase with reduced time steps efficiently for long-term simulations.

\section{ACKNOWLEDGMENTS}

The work was partially financially supported by the Harbor and Marine Technology Center (HMTC) Project: MOTCIOT-97-H2EB001.

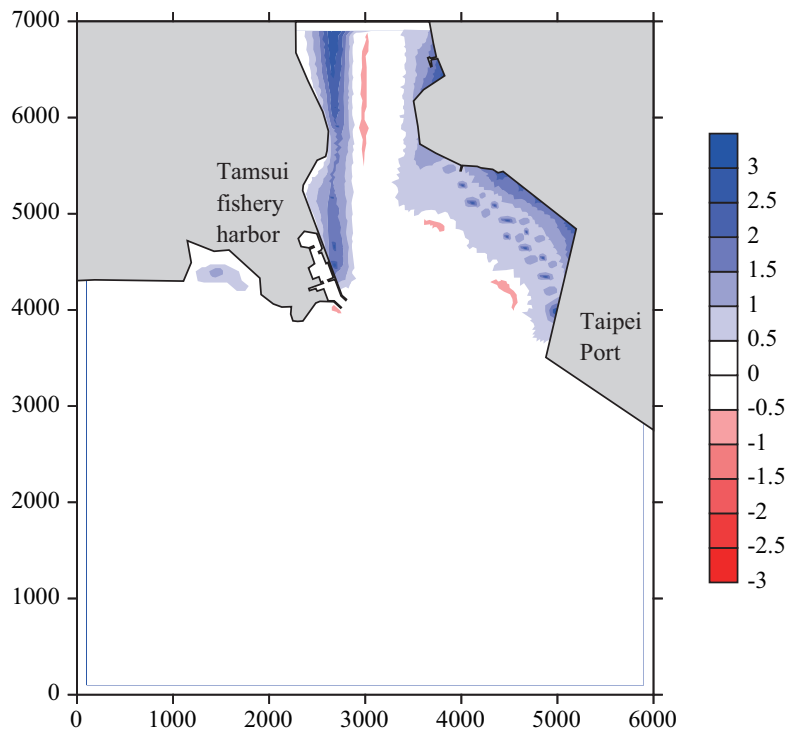

Fig. 13. The simulation of morphodynamic evolution without controlling oscillation schemes after one year.

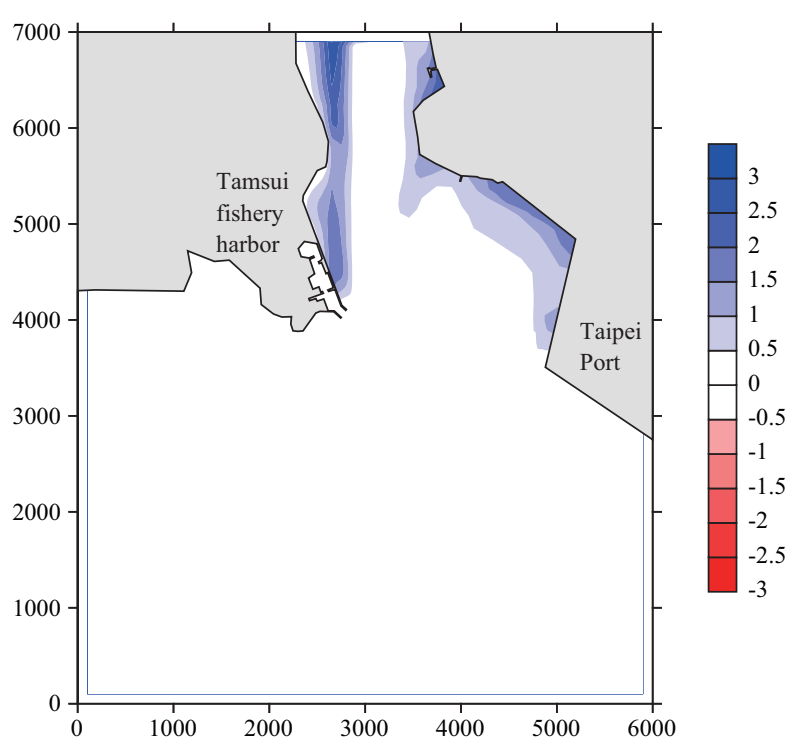

Fig. 14. The simulation of morphodynamic evolution with controlling oscillation schemes after one year.

\section{REFERENCES}

1. Antunes Do Carmo, J. S. and Seabra-Santos, F. J., "Nearshore sediment dynamics computation under the combined effects of waves and currents," Advances in Engineering Software, Vol. 33, No. 1, pp. 37-48 (2002).

2. Callaghan, D. P., Saint-Cast, F., Nielsen, P., and Baldock, T. E., "Numerical solutions of the sediment conservation law; a review and improved formulation for coastal morphological modeling," Coastal Engineering, Vol. 53, pp. 557-571 (2006).

3. Cayocca, F., "Long-term morphological modeling of a tidal inlet: the arcachon basin France," Coastal Engineering, Vol. 42, No. 2, pp. 115-142 (2001).

4. Chiang, Y. C., Hsiao, S. S., and Lin, M. C., "Numerical solutions of coastal morphodynamic evolution for complex topography," Journal of Marine Science and Technology, Vol. 18, No. 3, pp. 333-344 (2010). 
5. Chiang, Y. C., Lin, M. C., and Liou, J. Y., “A model formula for estimation of the coastal sediments in west coast of Taiwan," Proceeding of the 18th Conference on Ocean Engineering in Republic of China, November 1996, pp. 619-626 (1996).

6. de Vriend, H. J., Capobianco, M., Chesher, T., De Swart, H. E., Latteux, B., and Stive, M. J. F., "Approaches to long-term modeling of coasta morphology: a review," Coastal Engineering, Vol. 21, pp. 225-269 (1993).

7. de Vriend, H. J., Zyserman, J., Nicholson, J., Roelvink, J. A., Péchon, P., and Southgate, H. N., "Medium-term 2DH coastal area modeling," Coastal Engineering, Vol. 21, pp. 193-224 (1993).

8. Fortunato, A. B. and Oliveira, A., "Improving the stability of a morphodynamic modeling system," Journal of Coastal Research, SI 50 (Proceedings of the $9^{\text {th }}$ International Coastal Symposium), Golden Coast, Australia, pp. 486-490 (2007).

9. Harten, A., "High resolution schemes for hyperbolic conservation laws," Journal of Computational Physics, Vol. 49, p. 357 (1983).

10. Harten, A., Engquist, B., Osher, S., and Chakravarthy, S., "Uniformly high-order accurate essentially non-oscillatory schemes III," Journal of Computational Physics, Vol. 71, pp. 231-303 (1987).

11. Jensen, J. H., Madsen, E. Ø., and Fredsøe, J., "Oblique flow over dredged channels: II. sediment transport and morphology," Journal of Hydraulic Engineering, Vol. 125, No. 11, pp. 1190-1198 (1999).

12. Jiang, G. S., Levy, D., Lin, C. T., Osher, S., and Tadmor, E., "Highresolution non-oscillatory central schemes with non-staggered grids for hyperbolic conservation Laws," SIAM Journal on Numerical Analysis, Vol. 35, No. 6, pp. 2147-2168 (1998).

13. Jiang, G. S. and Shu, C. W., "Efficient implementation of weighted ENO schemes," Journal of Computational Physics, Vol. 126, p. 202 (1996).

14. Jiang, G. S. and Wu, C. C., "A high-order WENO finite difference scheme for the equations of ideal magneto-hydrodynamics," Journal of Computational Physics, Vol. 150, pp. 561-594 (1999).

15. Johnson, H. K. and Zyserman, J. A., "Controlling spatial oscillations in bed level update schemes," Coastal Engineering, Vol. 46, pp. 109-126 (2002).

16. Kuroiwa, M. and Kamphuis, W. J., “A 3D morphodynamic model with shoreline change around coastal structures using a quasi-3D nearshore current model," Proceeding of Canadian Coastal Conference, Canadian, pp. 1-14 (2003).

17. Lin, M. C., Kuo, J. C., Chiang, Y. C., and Liou, J. Y., "Numerical modeling of topography changes in sea region," Proceedings of the 18th
Conference on Ocean Engineering in Republic of China, November 1996, pp. 627-637 (1996).

18. Liu, X. D., Osher, S., and Chan, T., "Weighted essentially non-oscillatory schemes," Journal of Computational Physics, Vol. 115, p. 200 (1994).

19. Long, W., Kirby, J. T., and Shao, Z., "A numerical scheme for morphological bed level calculations," Coastal Engineering, Vol. 55, pp. 167-180 (2008).

20. Maruyama, K. and Takagi, T., "A simulation system of nearshore sediment transport for the coupling of the sea-bottom topography, waves and currents," Proceedings of IAHR, Copenhagen (1988).

21. Nessyahu, H. and Tadmor, E., "Non-oscillatory central differencing for hyperbolic conservation laws," Journal of Computational Physics, Vol. 87, pp. 408-463 (1990).

22. Rakha, K. and Kamphuis, J. W., "A morphological model for eroding beach backed by a sea wall," Coastal Engineering, Vol. 30, No. 1, pp. 53-75 (1997).

23. Saint-Cast, F., "Modelisation de la morphodynamique des corps sableux en milieu littoral (Modelling of Coastal Sand Banks Morphodynamics)," $\mathrm{Ph}$. D. Thesis, University of Bordeaux I, Bordeaux, France, (2002).

24. Shao, Z. Y., Kim, S., and Yost, S. A., "A portable numerical method for flow with discontinuities and shocks," Proceedings of the 17th Engineering Mechanics Conference, ASCE, June 13-16. Paper, Vol. 65, University of Delaware, Newark, DE, USA (on CD) (2004).

25. Shu, C. W. and Osher, S., "Efficient implementation of essentially nonoscillatory shock-capturing schemes," Journal of Computational Physics, Vol. 77, pp. 439-471 (1988).

26. Struiksma, N., Olewesem, K. W., Flokstra, C., and de Vriend, H. J., "Bed deformation in curved alluvial channels," Journal of Hydraulic Research, Vol. 23, No. 1, pp. 57-79 (1985).

27. Tanguy, J. M., Zhang, B. N., and Hamm, L., "A new lax-wendroff algorithm to solve the bed continuity equation with slope effect," in: Spaulding, M. L. (Ed.), Estuarine and Coastal Modeling III, ASCE, pp. 134-148 (1993).

28. Watanabe, A., "Modeling of sediment and beach evolution," in: Horikawa, K. (Ed.), Nearshore Dynamics and Coastal Processes, University of Tokyo Press, Tokyo, Japan, pp. 292-302 (1988).

29. Williams, S. M. and Peregrine, D. H., "The overtopping of a plane slope by multiple swash events," in: Smith, J. M. (Ed.), Proceeding of the $28^{\text {th }}$ International Conference on Coastal Engineering, World Scientific, Singapore, Cardiff, Wales, pp. 929-941 (2002). 